\title{
OPTIMIZATION OF SOLAR PHOTOVOLTAIC AND DIESEL GENERATOR HYBRID SYSTEM
}

\author{
Puskar Suwal \\ Department of Electronics \& Communication Engineering, \\ Khwopa Engineering College, Purbanchal University, Nepal
}

\begin{abstract}
The techno-economic viability of a hybrid system of solar photovoltaic and diesel generator with the most likely stand-alone systems, i.e. diesel-powered system and solar photovoltaic system, has been analyzed for energy demand through optimization and sensitivity analys is using HOMER. The concept of hybridizing is that the base load is to be covered by largest and firmly available renewable energy source(s), and other intermittent source(s) should augment the base load to cover the peak load. The model has been designed to provide an optimal system configuration based on hour-by-hour data for energy availability and demands. Based on the simulation results, the hybrid system is found to be economically feasible enough to replace the stand-alone system currently practicing to fulfill the energy demand during power cut-off in Nepal.
\end{abstract}

Keywords: hybrid system, solar photovoltaic, diesel generator, optimization, total net present cost, cost of electricity

\section{Introduction}

Recurrent power cut-off (load shedding) has been among the most pressing issues that the country has been facing currently. The reason for unavoidable and recurrent load shedding has been progressive failure of the government and the development agencies tow ards generation of enough power to cope with the increasing power demand in domestic and industrial sectors. Progressively increasing durations of load shedding after the recession of monsoon has become obvious instrument of Nepal Electricity Authority (NEA), the nodal agency responsible for generation and transmission of electricity in Nepal. This has become more recurrent problem over last 10 years.

*Corresponding author: Puskar Suwal

Department of Electronics \& Communication Engineering,

Khwopa Engin eering College, Libali-2, Bhaktapur, Nepal

Email: puskarsuwal@gmail.com

(Received: 2013 Jan 02 Accepted: 2013 Oct 03)
According to NEA, there was no load shedding in the year 2005 and before 2003. But then during the time people were used to experiencing abrupt power cuts, low voltage supply and power fluctuations generally caused by sudden overload on the power system, routine maintenance work and damages to transmission line and distribution feeders due to natural calamities. Fig 1 shows the average weekly load shedding hours-trend from 2008 to 2013 in Nepal.

The load shedding is a function of the deficit of electricity between energy available and energy demand. Table 1 shows the annual load demand and available energy trend of Nepal, energy deficit of 494GWh in year 2011. With the current generation capacity of electricity $(718,621 \mathrm{~kW})$, the duration of load shedding as high as 18 hours a day in the peak of dry season has been beginning to be forecasted. 
There are multitudes of consequences of load shedding, affecting all sectors of economy, such as, industry, education, construction and business. All sections of population are also equally affected by recurrent load shedding events. This would also mean loss of livelihood to small entrepreneurs and poor and marginal sections of population who earn their living in the industries where production gets stopped due to power cut-off.

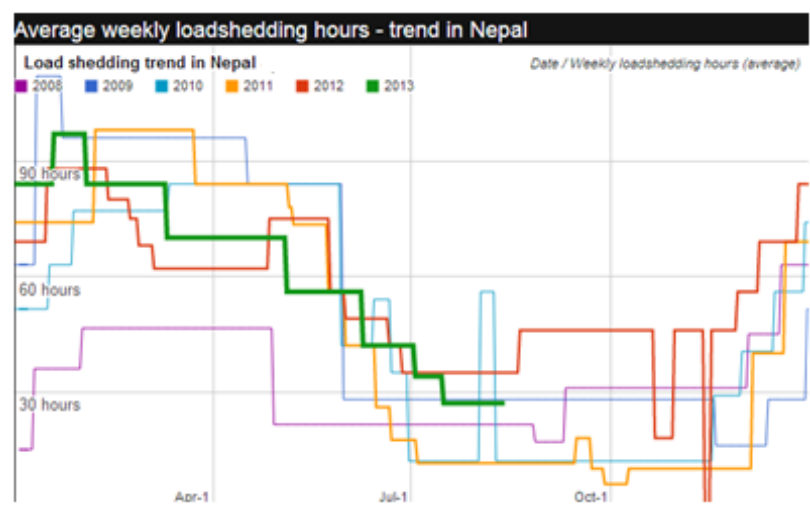

Fig 1 Average weekly load shedding hours -trend in Nepal (source: www.yalamandu.com)

Table 1: Load trend of Nepal (source: NEA, 2012)

\begin{tabular}{|c|c|c|c|}
\hline year & $\begin{array}{c}\text { Peak } \\
\text { Demand } \\
(\mathrm{MW})\end{array}$ & $\begin{array}{c}\text { Annual Load } \\
\text { Demand } \\
(\mathrm{GWh})\end{array}$ & $\begin{array}{c}\text { Total } \\
\text { Available } \\
\text { energy } \\
(\mathrm{GWh})\end{array}$ \\
\hline 2002 & 426 & $1,959.60$ & $2,066.45$ \\
\hline 2003 & 470.33 & $2,163.52$ & $2,261.13$ \\
\hline 2004 & 515.24 & $2,370.10$ & $2,380.90$ \\
\hline 2005 & 557.53 & $2,564.64$ & $2,642.75$ \\
\hline 2006 & 603.28 & $2,775.09$ & $2,780.92$ \\
\hline 2007 & 648.39 & $2,982.59$ & $3,051.82$ \\
\hline 2008 & 721.73 & $3,319.96$ & $3,185.95$ \\
\hline 2009 & 812.5 & $3,737.50$ & $3,130.79$ \\
\hline 2010 & 885.28 & $4,072.29$ & $3,711.77$ \\
\hline 2011 & 946.1 & $4,352.06$ & $3,858.37$ \\
\hline
\end{tabular}

Some of technologies have been in practices to avoid the effect of load shedding. Diesel Generator (DG) is one of them. Diesel generator generates the needed electricity in absence of grid electricity. Diesel generator consumes diesel to operate. Nepal Oil
Corporation (NOC) has claimed that the country has been generating around 531 megawatt (MW) of electricity through the use of diesel (May 2012). According to them, around 30 to 40 per cent of diesel has been utilized to generate electricity during loadshedding. Despite of providing electricity in absence of grid, using diesel generator is not comfortable as it has some serious drawbacks.

The key issues faced by DG are the variation in the load, and its operative cost. Severe variation in the load results in poor engine performance. The generator performs efficiently when it is operating close to its rated capacity. Continued operation at lower loads results in an inefficient plant performance and higher cost of energy (Arun et.al, 2008). One of the methods suggested by manufactures to prevent part load operation is the use of dummy loads, where resistive load banks are used to absorb the excess to keep the engine loading high. However, such methods are not energy efficient. Integration of battery banks with DG improves the system efficiency. Peak load is met by the DG together with inverter operating in parallel. It allows operation of the DG at the full load condition and thus, enabling efficient operation of the generator. It is important to study the optimal generator dispatch and battery charge-discharge scheduling from the system operation point of view. Optimal operation of such systems has been studied using methods such as simulated annealing (Nayar, 1995).

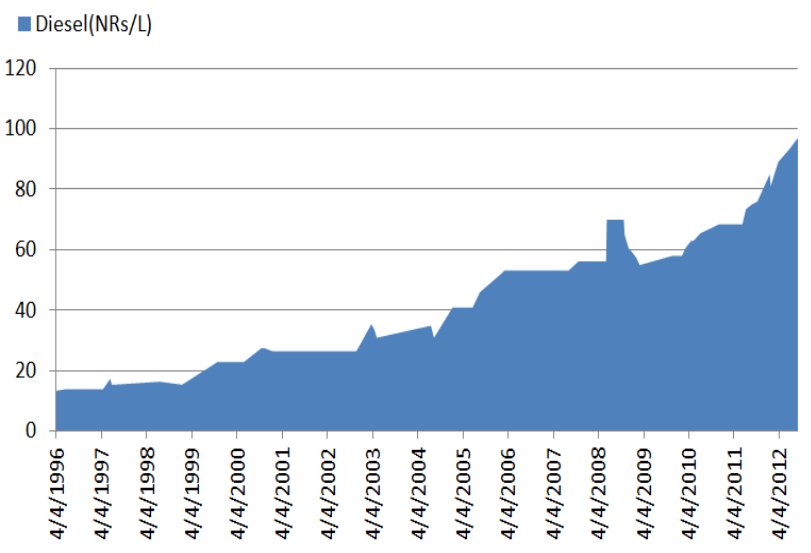

Fig 2 Price trend of diesel (source: NOC, 2012) 
According to NOC, the cost per unit of electricity stands at around Rs. 25 to Rs. 30 for diesel-generated electricity (May 2012). Fuel used in DG is not locally available and has to be imported from foreign country. Reports have shown that nations' $50 \%$ revenue is expensed in importing such fuel. Moreover the cost of fuel is increasing rapidly and forecasted to increase more rapidly than nowadays. Fig 2 shows the trend of diesel cost in Nepal.

Another technology being used to avoid the load shedding is Solar Photovoltaic (SPV). SPV system includes solar module, battery as backup storage, charge controller and converter (if nec essary). It uses sun light as its energy source to produce electricity. The amount of power produced by photovoltaic cells varies significantly on an hourly, daily and seasonal basis due to the variation in the availability of sun. This variation means that sometimes power is not available when it is required, and on other occasions there is excess power. To deliver continuous uninterrupted power supply, the photovoltaic (PV) array and battery of a standalone solar photovoltaic system have to be excessively over-sized leading to high capital cost. For undersized systems, power shortages will be experienced and the batteries may be damaged by excessive discharge.

The certainty of meeting load demands at all times is greatly enhanced by the hybrid system using DG and SPV. In this paper, the author analyses the optimum configuration of SPV/DG hybrid system. The optimum configuration indicates the optimum PV array and diesel generator capacities that lead to minimum system cost.

\section{Choice of software}

Analys is is done by us ing HOMER software (Hybrid Optimization Model for Electric Renewable). This software which simulates the different operating conditions was developed by the National Renewable Energy Laboratory (U.S.) and has been used for choosing, in an optimal way, the various components of the plant.
One of the major applications of HOMER is the design of micro-power systems for the efficient evaluation of various renewable energy power generation technologies. It compares wide range of equipment with different constraints and sensitivities to optimize the system design. Simulation, optimization and sensitivity are the three major actions run by HOMER. In the simulation process, different micro-power system configurations for every hour of the year are generated with their technical feasibility and life cycle cost (LCC). In the optimization process, it selects one system configuration out of all configuration generated in the simulation process that satisfies all technical constraints and has the lowers LCC. In the sensitivity analysis, multiple optimizations are preferred on the selected configurations by HOMER with a range of uncertain input parameters that is assumed to affect the model inputs with time.

As HOMER does both optimization and sensitivity analysis it makes easier to evaluate many possible system configurations of the large number of technology options and the variation in technology cost and availability of energy resources. It produces results in the shape of feasible configuration according to the increase in the Net Present Cost (NPC). The best configurations have been compared and examined on their economic and technical merits.

\section{System configuration}

The hybrid system consists of diesel generator, solar array as energy sources, battery as a storage device and converter for converting power produced from the energy sources as shown in Fig 3. The primary load is supposed to be AC load and is tied to AC bus. The output from generator is alternating in nature, hence it is tied to AC bus bar and the output of solar panel is DC in nature and is tied to DC bus bar. The battery is also tied to DC bus bar so that it can store the power delivered by solar panel when there is excess solar radiation during peak sun hours and deliver the required amount of power when the solar panel is not 
in operation. The converter is tied between AC and DC bus bar as it is bidirectional converter.

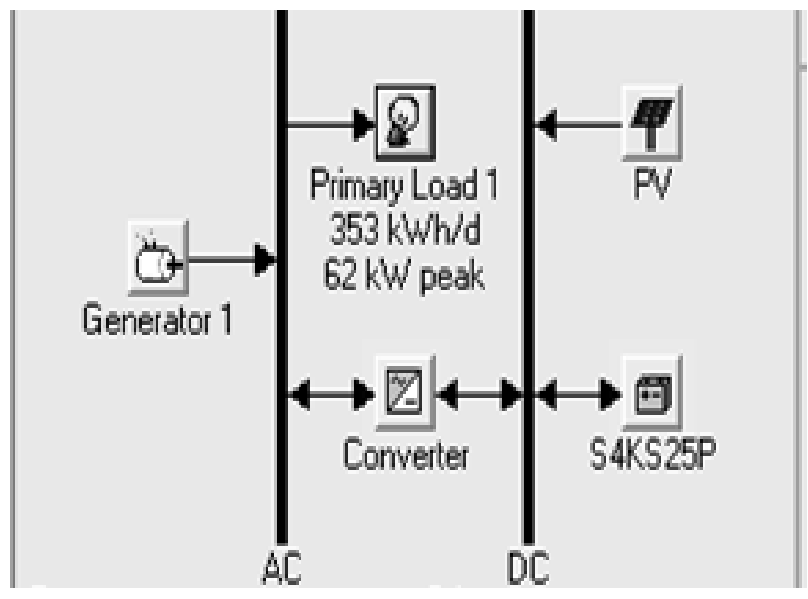

Fig 3 Hybrid system configuration

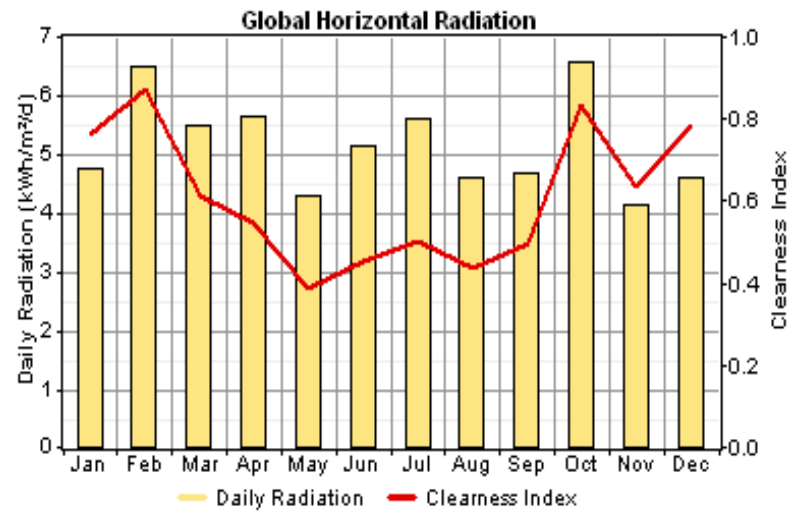

Fig 4 Monthly average ground measured global horizontal solar irradiance at $27^{\circ} 59^{\prime} \mathrm{N}$ and $85^{\circ} 38^{\prime} \mathrm{E}$.

\section{Input parameters}

\subsection{Energy Resources}

As mentioned above, the energy resource considered in this work is diesel fuel (for DG) and sun light (for SPV). The solar resource input for the various months throughout the year is obtained from the report provided by Alternative Energy Promotion Center (AEPC). According to the report, Nepal is located at favorable latitude that receives ample amounts of solar radiation. On average Nepal has 6.8 sunshine hours per day, i.e. 2482 sunshine hours per year (Shrestha et.al, 2006). Fig 4 shows the monthly average ground measured horizontal solar radiation data and clearness index of Kathmandu valley located at $27^{\circ} 59^{\prime} \mathrm{N}$ and $85^{\circ} 38^{\prime} \mathrm{E}$. The scaled annual average daily solar radiation is $5.12 \mathrm{kWh} / \mathrm{m}^{2} /$ day (SWERA, 2005).

The cost of diesel fuel needed for the operation of generator is changing rapidly these days. The fuel cost on February 2012 is Rs. 97/L. Some properties of fuel are:

Lower heating value:

$43.2 \mathrm{MJ} / \mathrm{kg}$

Density: $820 \mathrm{~kg} / \mathrm{m}^{3}$

Carbon content: $\quad 88 \%$

Sulfur content: $\quad 0.33 \%$

The intercept coefficient and slope of the generator are considered to be $0.06 \mathrm{~L} / \mathrm{hr} / \mathrm{kW}$ rated and $0.22 \mathrm{~L} / \mathrm{hr} / \mathrm{kW}$ output respectively.

\subsection{Load profile}

The load demand is supposed to be $309 \mathrm{kWh} /$ day with $62 \mathrm{~kW}$ as a peak demand. Seasonal profile and daily profile of the load demand is shown in Fig 5 and Fig 6 respectively. Load is constant throughout the year. The baseline data of load is considered as same for all the months and random variability of $5 \%$ each is considered for day-to-day and time-step-to-time-step.

\subsection{System components}

In a micro-power system, a component generates, delivers, converts and stores energy. In this work, SPV is the major energy source with DG for backup. Batteries and converters are used for storing, respectively converting, electricity. The performance and cost of each of the system's components are a major factor for the cost results and the design. The components' technical and cost parameters for this study are based on data collected from previous published literatures, information from personal sources of Nepali market, and assumptions. 


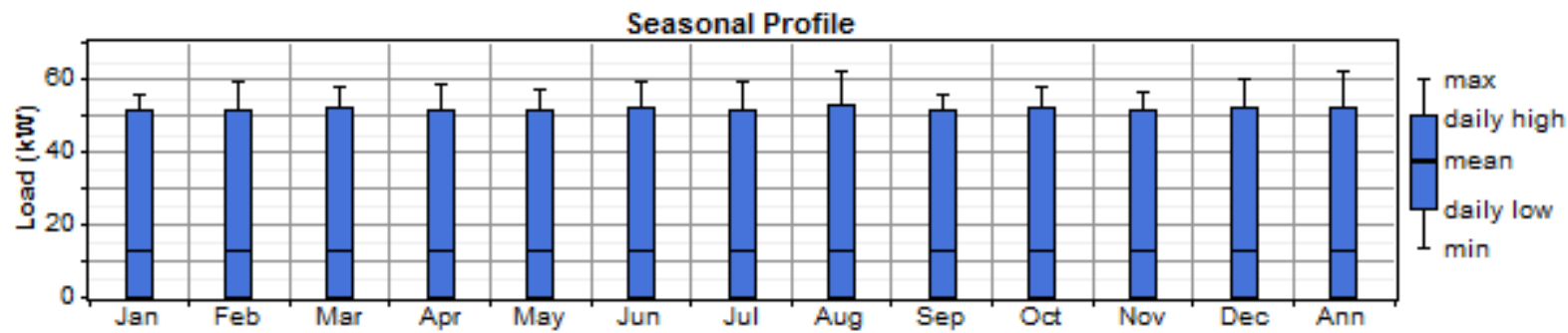

Fig 5 Seasonal load profile

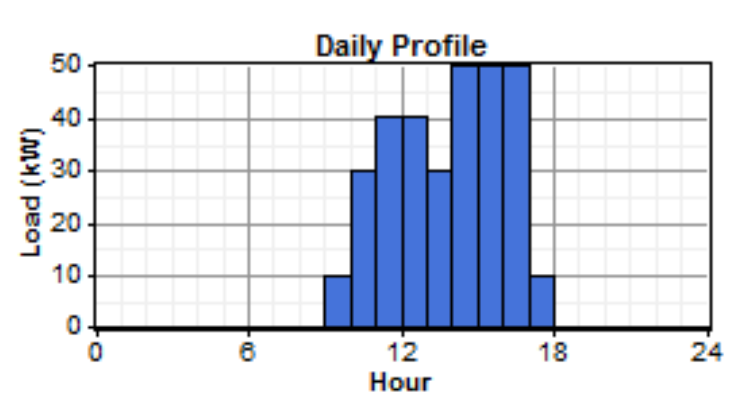

Fig 6 Daily load profile

\section{A. Solar photovoltaic panel}

The SPV panels are connected in series/parallel. When the sunlight is incident on a SPV panel it produces electricity. The initial cost of solar panel is Rs. $1,15,000$ per kilowatt and need to replace in every 25 years. The O\&M cost of solar panel is very low compared to other costs (Rs. 1,000 per year). The derating factor considered is $80 \%$ for each panel to approximate the varying effects of temperature and dust on the panels. The panels have no tracking system and are modeled as fixed tilted south with the slope of $32^{0}$.

\section{B. Generator}

The initial cost and the replacement cost of $60 \mathrm{~kW}$ generator considered is Rs. 9,00,000 each and O\&M cost is Rs. 130 per hour. Life time of the generator is 15,000 operating hour and minimum load ratio is $30 \%$.

\section{Storage device}

For the purpose of the storage and maintaining a constant voltage, batteries are used. HOMER models a number of individual batteries to create a battery bank connected in series-parallel connections. The battery Surrette 4KS25P is employed as a storage device for this hybrid system. The initial cost and the replacement cost of this battery is Rs. 2,30,000 each and the O\&M cost is Rs. 1,000 per year. Some other properties of the battery are as follows:

Nominal Capacity: 1900 Ah

Nominal Voltage: 4V

Round trip Efficiency: 80\%

Minimum State of Charge: $40 \%$

Minimum Battery Life: 5 yrs

Lifetime throughput: $10569 \mathrm{kWh}$

Suggested value: $10494 \mathrm{kWh}$

Maximum charge rate: $1 \mathrm{~A} / \mathrm{Ah}$

Maximum charge current: $67.5 \mathrm{~A}$

\section{Converter}

A converter is used to maintain the energy flow between $\mathrm{AC}$ and $\mathrm{DC}$ electrical components. The converter used for this model is bidirectional, that is, it can convert $\mathrm{AC}$ to $\mathrm{DC}$ as well as $\mathrm{DC}$ to $\mathrm{AC}$. The initial cost and the replacement cost of the converter is Rs. 12,000 per kilowatt each and the O\&M cost is Rs. 1,000 per year. Lifetime of the converter is 10 years, and is $90 \%$ efficient.

\subsection{Equipment considered}

The search space shows the list of component size considered in the analysis to design the correctly sized hybrid system. Table 2 shows the search space of components used in the system.

\subsection{Economic input}

As it is HOMER's aim to minimize the total net present cost both in finding the optimal system configuration and in operating the system, economics play a crucial role in the simulation. The project life time is considered to be 20 years with an annual 
interest rate of $6 \%$. The nominal interest rate minus the inflation rate gives the real interest rate. HOMER factors inflation out of the analysis with the help of the assumption that prices will increase at the same rate during the system's life span.

Table 2 Search space of co mponents

\begin{tabular}{|r|r|r|r|}
\hline $\begin{array}{r}\text { PV } \\
\text { array }\end{array}$ & DG & S4KS25P & converter \\
\hline $\mathbf{( k \mathbf { W } )}$ & $\mathbf{( k \mathbf { W } )}$ & (quantity) & $\mathbf{( k \mathbf { W } )}$ \\
\hline 0 & 0 & 0 & 0 \\
\hline 40 & 20 & 12 & 20 \\
\hline 60 & 30 & 24 & 40 \\
\hline 80 & 40 & 48 & 60 \\
\hline 100 & 50 & 60 & 80 \\
\hline 120 & 60 & 72 & 100 \\
\hline 140 & 80 & 84 & 120 \\
\hline 160 & 100 & 96 & \\
\hline 180 & & 108 & \\
\hline 200 & & 120 & \\
\hline 220 & & & \\
\hline 240 & & & \\
\hline 260 & & & \\
\hline
\end{tabular}

\subsection{System control}

Two different types of control strategies are modeled by HOMER: Load-following (LF) strategy and Cycle charging (CC) strategy. The generator is only allowed to generate power to meet the load at a given time in LF strategy. And in CC strategy, the generator is allowed to operate up to maximum power to charge the batteries and serve the load at the same time. In this study, both types of strategies have been selected. The set point charge for the batteries is kept at $80 \%$.

\subsection{Sensitivity inputs}

HOMER is able to conduct a sensitivity analys is on hourly data sets with the help of scaling variables. The uncertain variables for which a sensitivity analysis is to be conducted are the diesel price, SPV capital investment, SPV replacement cost and useful life of the study. Table 3 shows the parameters and its values inputted for this system. As diesel price and SPV cost are changing in today's market, author assumed that this change will continue in future also. And the project life is also listed in sensitive parameter as it affects in the NPC cost of the system. For each of these different values the complete system is simulated with the resulting different technical and cost parameters.

Table 3 Sensitivity inputs

\begin{tabular}{|r|r|r|r|}
\hline Diesel & PV cap. & PV rep. & $\begin{array}{r}\text { Project } \\
\text { Life }\end{array}$ \\
\hline (Rs./L) & Multiplier & Multiplier & (year) \\
\hline 96 & 1 & 1 & 20 \\
\hline 120 & 0.9 & 0.9 & 25 \\
\hline 135 & 0.8 & 0.8 & 30 \\
\hline & 0.7 & 0.7 & \\
\hline
\end{tabular}

\section{Result and Analysis}

Once the previously described specifications have been input to HOMER, this software performs calculations to determine the best combination that technically and economically meets the load demand. The optimization results of the hybrid system of diesel and photovoltaic using HOMER is shown in Fig 7. All the possible system configurations are listed in ascending order of their total net present cost (NPC).

In Fig 7, the results show that use of $120 \mathrm{~kW}$ solar photovoltaic and $20 \mathrm{~kW}$ generator with 12 numbers of S4KS25P storage devices and $60 \mathrm{~kW}$ converter with CC dispatch strategy is economically beneficial than isolated standalone systems. Total net present cost of the system is calculated to be Rs. 2,43,89,190 and cost of electricity is Rs. $19.416 / \mathrm{kWh}$. For the given load profile, 20kW DG is operated 1,310 hours a year which consumes 6,109 liters diesel fuel. The percentage share of renewable energy (photovoltaic) is $89 \%$ in this combination. 
The photovoltaic standalone system costs Rs. $3,35,09,952$ and cost of electricity is Rs. $26.756 / \mathrm{kWh}$, nearly 1.4 times costly than the hybrid system. Similarly, standalone diesel generator without battery backup costs Rs. 4,80,22,676 and cost of electricity is Rs. $37.127 / \mathrm{kWh}$, nearly 1.9 times the hybrid system.

Fig 8 shows the monthly distribution of the electricity produced in $\mathrm{kW}$ by SPV and DG. In February and October, SPV is mostly used as in that months, daily radiation is high compared to other months. The effect of SPV penetration reduces the diesel fuel consumption. As the output from the PV increases, the generator's operation hours decrease. In the months when SPV output is high, DG is not used at all. The amount of electricity production from SPV and DG is shown in table 4. It shows that total electricity production per year is $1,95,366 \mathrm{kWh}$ and excess electricity is $38.1 \%$ of total electricity generated. Most of the excess electricity is generated at the months when daily radiation is comparatively high. This shows that this system has the capability in meeting the demand growth in the future.

\begin{tabular}{|c|c|c|c|c|c|c|c|c|c|c|c|c|c|}
\hline 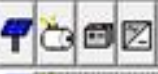 & $\begin{array}{c}\text { PV } \\
(\mathrm{kW})\end{array}$ & $\begin{array}{c}\mathrm{DG} \\
(\mathrm{kW})\end{array}$ & S4KS25P & $\begin{array}{l}\text { Conv. } \\
(\mathrm{kW})\end{array}$ & $\begin{array}{l}\text { Disp. } \\
\text { Strgy } \\
\end{array}$ & $\begin{array}{l}\text { Intial } \\
\text { Capital }\end{array}$ & $\begin{array}{l}\text { Operating } \\
\text { Cost }\end{array}$ & $\begin{array}{l}\text { Total } \\
\text { NPC } \\
\end{array}$ & COE & $\begin{array}{l}\text { Ren. } \\
\text { Frac. } \\
\end{array}$ & $\begin{array}{l}\text { Capacity } \\
\text { Shortage }\end{array}$ & $\begin{array}{l}\text { Diesel } \\
\text { (L) }\end{array}$ & $\begin{array}{l}\text { DG } \\
\text { (hrs) }\end{array}$ \\
\hline $3 \Theta \square$ & 100 & 20 & 12 & 60 & $\infty$ & 15.280 .000 & 794.181 & 24.389 .190 & 19.416 & 0.89 & 0.05 & 6.109 & 1.310 \\
\hline 2 & 120 & 30 & & 60 & $\subset C$ & 14.970 .000 & $1,046,319$ & $26,971.190$ & 21.225 & 0.89 & 0.05 & 9.146 & 1.790 \\
\hline 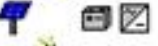 & 220 & & 24 & 60 & $\subset \subset$ & $31,540,000$ & 171,749 & $33,509,952$ & 26.756 & 1.00 & 0.05 & & \\
\hline 0 & & 50 & & & $\propto$ & 750,000 & $3,859,553$ & $45,018,764$ & 35.237 & 0.00 & 0.05 & 35.165 & 3.285 \\
\hline 凹曰 & & 50 & 12 & 20 & $\subset$ & 3.750 .000 & $3,859,894$ & $48,022,676$ & 37.127 & 0.00 & 0.00 & 34.344 & 2.916 \\
\hline
\end{tabular}

Fig 7 Optimization results

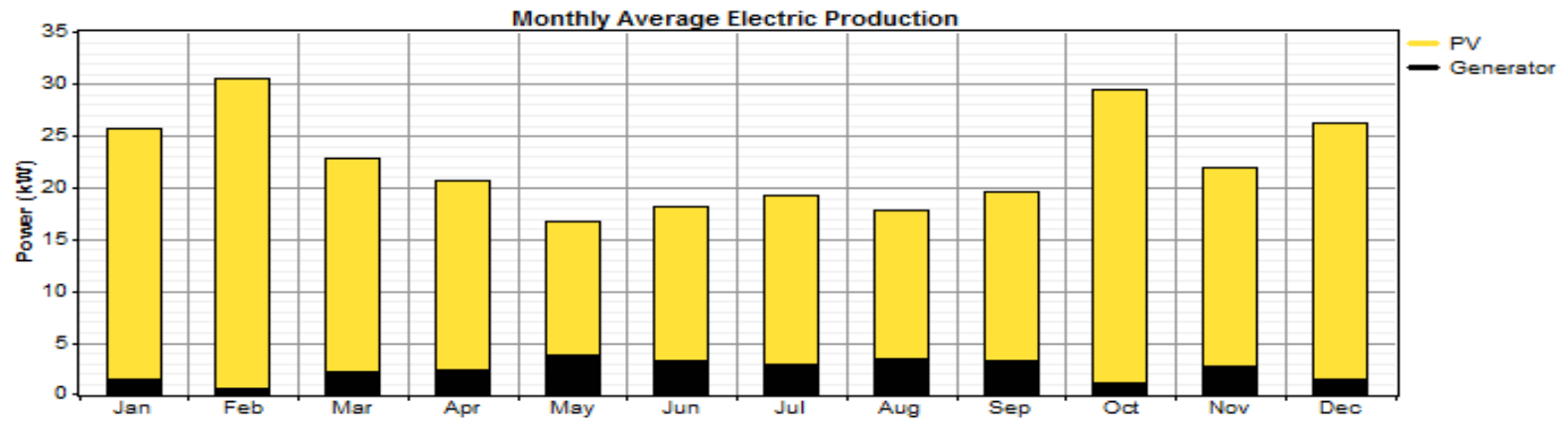

Fig 8 Monthly average electricity production from SPV and DG

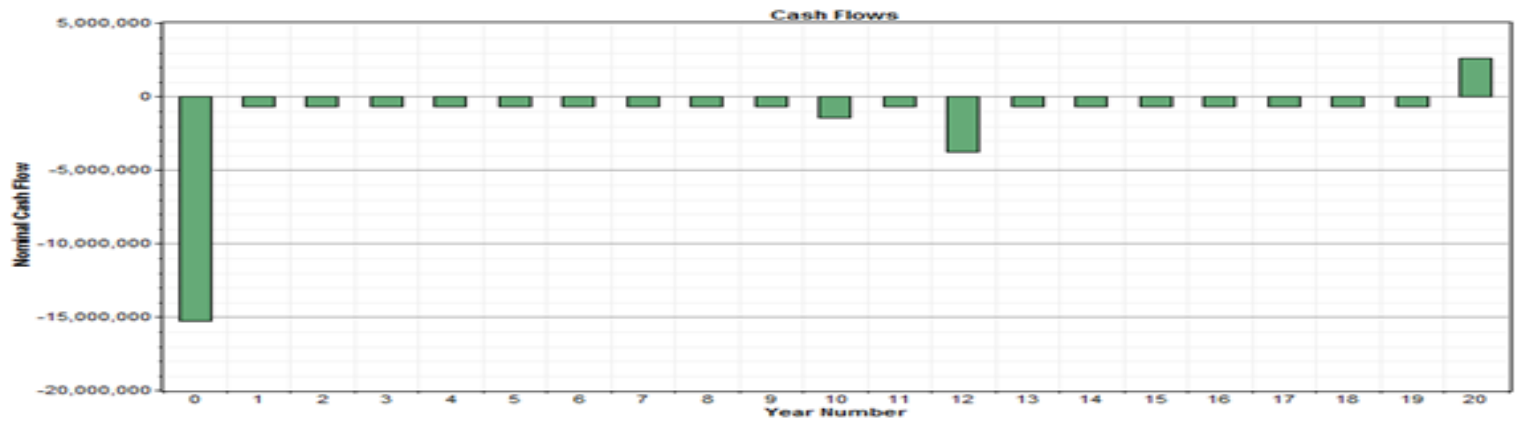

Fig 9 Cash flow diagram of the SPV/DG hybrid system 
Fig 9 and Fig 10 respectively show the cash flow diagram and percentage contribution of each component of the SPV/DG hybrid system. It can be seen that $45 \%$ of total cost is of SPV and occurs at the investment time, whereas during the operation time, cost for SPV is almost nil as SPV is cheap to maintain and operate compared to DG. O\&M cost of the system is covered mainly by generator cost (including the fuel cost) and SPV and batteries cost share the maximum portion of the capital investment. Replacement costs occur majorly in the $10^{\text {th }}$ and $12^{\text {th }}$ year of the system, mostly for batteries, as well as converter and generator.

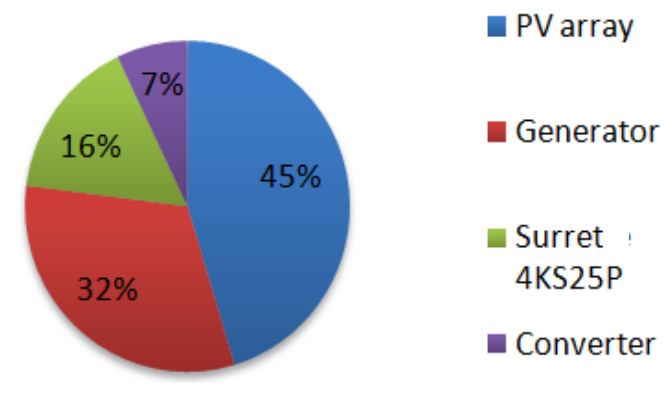

Fig 10 Percentage contribution of component of the hybrid system on total cost

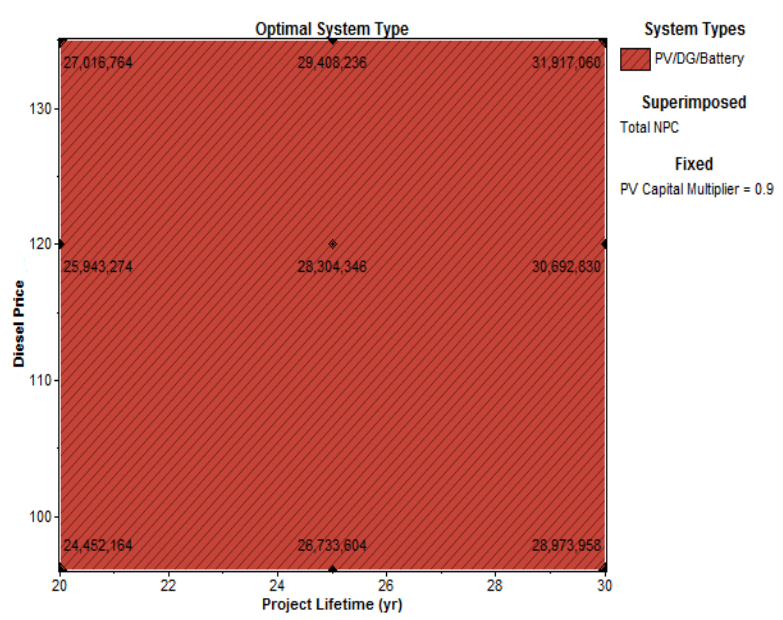

Fig 11 Optimal system type

Sensitivity analysis of the hybrid system is done considering diesel price, PV capital cost, PV replacement cost and project life as uncertain parameters. Fig 11 shows the optimum system type for changing uncertain parameters. It can be observed from the figure that the PV/DG hybrid system with battery backup is preferred for all cases of changing uncertain parameters.

Table 4 summary of SPV/DG hybrid system

\begin{tabular}{|l|r|r|}
\hline Production & \multicolumn{1}{|c|}{$\mathrm{kWh} / \mathrm{yr}$} & \multicolumn{1}{|l|}{$\%$} \\
\hline PV array & $1,74,744$ & 89 \\
\hline Generator & 20,622 & 11 \\
\hline Total & $1,95,366$ & 100 \\
\hline
\end{tabular}

\begin{tabular}{|l|l|l|}
\hline Consumption & $\mathrm{kWh} / \mathrm{yr}$ & $\%$ \\
\hline $\begin{array}{l}\text { AC primary } \\
\text { load }\end{array}$ & $1,09,518$ & 100 \\
\hline Total & $1,09,518$ & 100 \\
\hline
\end{tabular}

\begin{tabular}{|l|r|r|}
\hline Quantity & $\mathrm{kWh} / \mathrm{yr}$ & \multicolumn{1}{l|}{} \\
\hline $\begin{array}{l}\text { Excess } \\
\text { electricity }\end{array}$ & 74,433 & 38.1 \\
\hline $\begin{array}{l}\text { Unmet electric } \\
\text { load }\end{array}$ & 3,267 & 2.9 \\
\hline $\begin{array}{l}\text { Capacity } \\
\text { shortage }\end{array}$ & 5,590 & 5 \\
\hline
\end{tabular}

\begin{tabular}{|l|r|}
\hline Quantity & Value \\
\hline $\begin{array}{l}\text { Renew able } \\
\text { fraction }\end{array}$ & 0.894 \\
\hline
\end{tabular}

Fig 12 shows the surface plot for the levelized cost of electricity (COE) with total NPC superimposed. The project life is fixed at 20 years; PV capital multiplier is depicted on y-axis and diesel price on $\mathrm{x}$-axis. It can be observed that as diesel price increases, operating cost of generator increases and hence increase in COE as well as total NPC. Similarly decrease in PV capital cost decreases the COE and total NPC of the system. If the PV capital cost reduces by $30 \%$ and diesel price remain same for the study period, COE will be Rs. 17.5/kWh. Fig 13 shows the surface plot for levelized COE with fixed PV capital multiplier (1).

From the figure, it is clear that COE is least (Rs. $19 / \mathrm{kWh}$ ) when project life is 25 years regardless of diesel price. This shows that with the change in sensitivity parameters, the total NPC and levelized COE also change. 


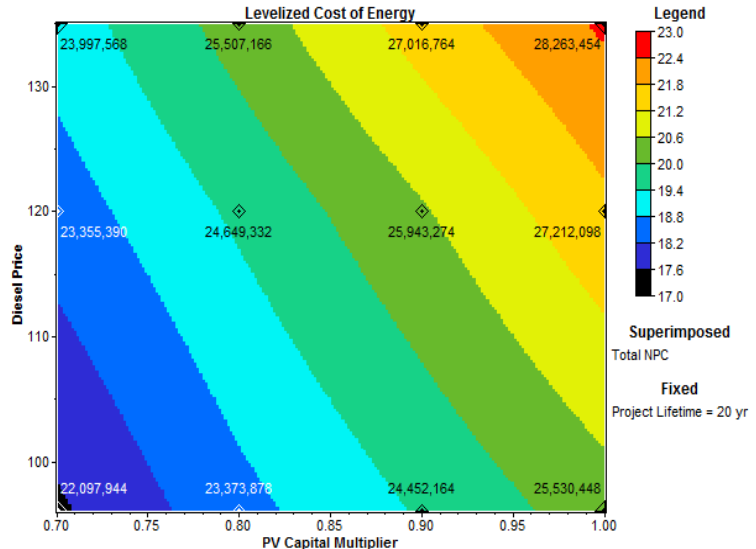

Fig 12 Surface plot for levelized COE with 20 year fixed project life.

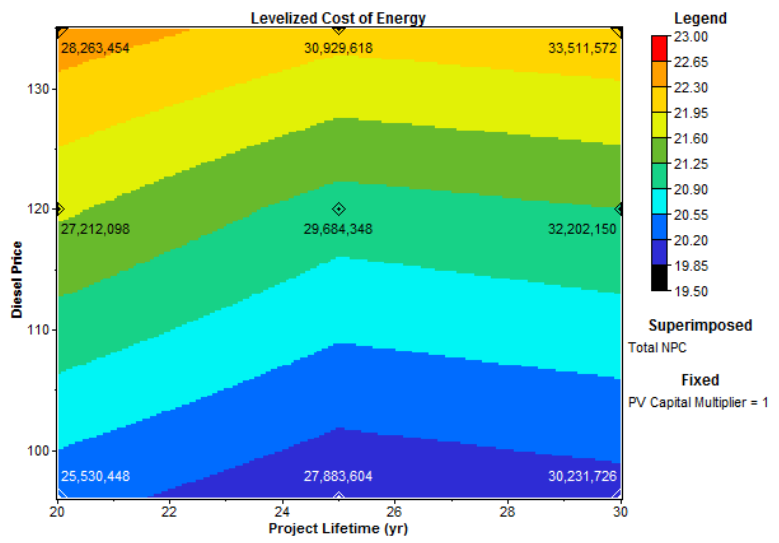

Fig 13 Surface plot for levelized COE with fixed PV capital multiplier.

Hence from this optimization model, the project life of proposed hybrid system for the given load shou. be 25 years and should constitute $120 \mathrm{~kW}$ SPV, 20kW DG with 12 numbers of Surrette S4KS25P batteries and $60 \mathrm{~kW}$ converter and $\mathrm{CC}$ dispatch strategy.

\section{Conclusion}

To cope up with the load shedding currently facing, by the Nepalese people, the above proposed SPV/DG hybrid system with battery backup is the most viable option. In this study, a resource assessment has been carried out and the COE per unit has been ascertained for different systems and configurations using HOMER software. A combination of SPV, DG with battery backup has been identified as the cheapest and most dependable solution with a COE of Rs. $19.416 / \mathrm{kWh}$ if the project life is considered to be 20 years and Rs. $19 / \mathrm{kWh}$ if the project life is 25 years. However, this is still expensive (compared to grid) and difficult to combine various energy sources together. The simulated hybrid system can be used in any area of Nepal as solar radiation is used as primary source of energy which is abundant throughout the country.

\section{References:}

[1] P. Arun, Rangan B anerjee, Santanu Bandy opadhy ay, 2008. Optimum sizing of battery-integrated diesel generator for remote electrification through designspace approach, ScienceDirect, Energy 33, pp 11551168

[2] Nayar CV, 1995. Recent developments in mini-grid diesel power systems in Australia, Appl Energy; 52:229-42

[3] Shrestha, J.N. et.al, 2006. Solar Radiation in Nepal: Its implications in Telecommunication Services, Proceedings of First National Conference in Renewable Energy Technology for Rural Development, Center for Energy Studies, Institute of Engineering, T.U.

[4] Government of Nepal, Ministry of Environment, science, Science and Technology, Alternative Energy Promotion Center, 2005. Solar and Wind Energy Resource Assessment (SWERA) in Nepal.

[5] Nepal Electricity Authority, 2012. Fiscal year 2011/2012 - A year in review 